\title{
What does the Chronic Pain Grade Questionnaire Measure?
}

\author{
Authors: $\quad$ Diane Dixon ${ }^{\mathrm{a}}$; Beth Pollard ${ }^{\mathrm{b}}$; Marie Johnston ${ }^{\mathrm{b}}$

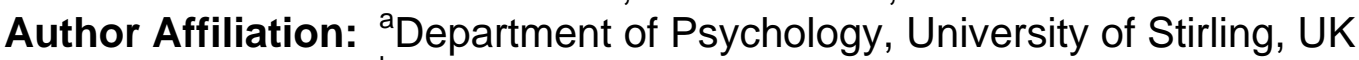 \\ ${ }^{b}$ Institute of Applied Health Sciences, University of Aberdeen, \\ UK \\ Number of \\ Text Pages: 19 (including figures and tables which are each on separate \\ pages) \\ Number of Figures \\ And Tables: 1 Figure and 3 Tables \\ Corresponding \\ Author: \\ Diane Dixon \\ Department of Psychology, University of Stirling, Stirling, FK9 \\ 4LA, UK. Telephone: +44(0)1786 466840. FAX: +44(0)1786 \\ 467641. e-mail: diane.dixon@stir.ac.uk. URL: \\ http://www.psychology.stir.ac.uk/staff/ddixon/index.php
}




\begin{abstract}
This study explored the ability of the Chronic Pain Grade Questionnaire (CPG) to operationalise the WHO's model of health outcomes, namely the International Classification of Functioning, Disability and Health (ICF). Twelve expert judges used the method of discriminant content validation to allocate the 7 items of the CPG to one or more ICF outcome, namely, impairment, activity limitations and participation restrictions. One-sample t-tests classified each item as measuring impairment, activity limitations or participation restrictions, or a combination thereof. The results indicated that the CPG contains items able to measure each of the three ICF outcomes. However, the pain grade classification system used in the CPG conflates the ICF outcomes. The implication of this conflation of outcome for the assessment of interventions is discussed.
\end{abstract}

Abstract Word Count: 123

Introduction Word Count: 497

Discussion Word Count: 924 


\section{Introduction}

The chronic pain grade questionnaire (CPG) is a 7-item instrument frequently used to measure chronic pain in epidemiological studies (Vonkorff, Dworkin et al. 1990; Vonkorff, Ormel et al. 1992;Elliott, Smith et al. 1999). The CPG classifies respondents into one of five hierarchical pain grades: pain free (grade 1), low disability and low intensity (grade 2), low disability, high intensity (grade 3), high disability, moderately limiting (grade 4) and high disability, severely limiting (grade 5). However, the CPG was not developed within a specific theoretical framework and was generated prior to the publication of the WHO's International Classification of Functioning Disability and Health (ICF) (WHO 2001). The ICF aims to provide a standard framework for the comparison and understanding of health outcomes. For any given health condition, such as chronic pain, the ICF identifies three main outcomes, namely, impairment (I), activity limitations (A) and participation restrictions (P) (see Figure 1). The potential importance of the ICF to inform both assessment and intervention in rehabilitation medicine has been recognised (Steiner, Ryser et al. 2002; Finger, Cieza et al. 2006). That said the utility of the ICF will depend upon its compatibility with outcome measures in current use (Stucki, Ewert et al. 2003). Consequently, there is a need to establish the relationship between the three ICF outcomes and the 5 grades of the CPG.

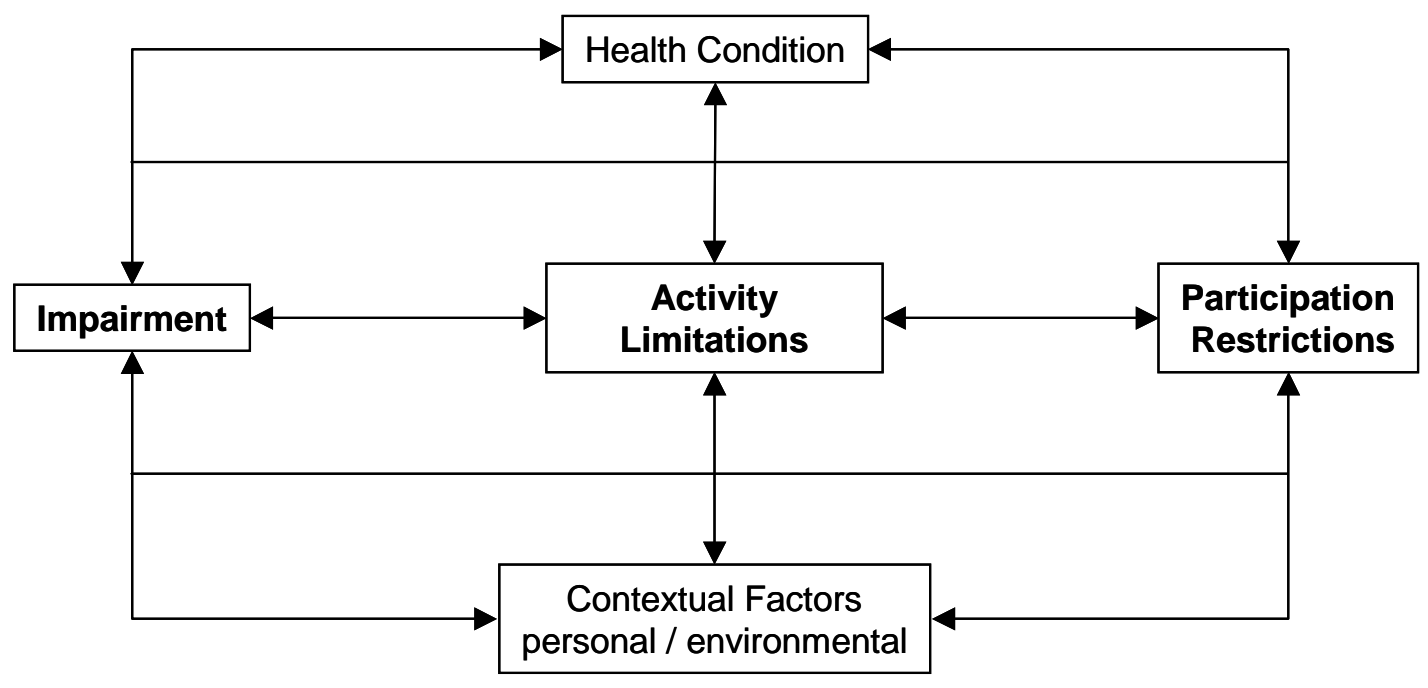

Figure 1: The International Classification of Functioning Disability and Health (ICF)

Core measurement sets which identify the minimum set of measures required for the assessment of functioning and health for a given health condition including chronic widespread pain and lower back pain are being developed (Cieza, Stucki et al. 2004b). In addition, existing health outcome measures have been examined for their ability to operationalise the ICF (Cieza, Brockow et al. 2002;Weigl, Cieza et al. 2003;Brockow, Cieza et al. 2004;Pollard, Johnston et al. 2006). This work revealed that many existing instruments measure more than one outcome (Pollard, Johnston, and Dieppe 2006). It is possible that the CPG may similarly conflate outcomes, for example, the conflation of $I$ and $A$ in grades 2 and 3 and $A$ and $P$ in grades 4 and 5 . Conflation of outcome may be especially important when instruments, such as the CPG, assess the effect of interventions. For example, an intervention that fails to improve impairment or activity limitations but increases patient valued social participation may appear ineffective unless independent measures of all three 
outcomes are available. Consequently, a precise understanding of the outcomes instruments such as the CPG measure would be useful.

Recently a method of establishing the content validity of health outcome measures has been developed (Johnston and Pollard 2001). This method of Discriminant Content Validation (DCV) examines the relationship between individual measurement items and the theoretical definition of the construct they aim to measure. This method has successfully examined the relationship between orthopaedic, pain and quality of life measures, and the three main health outcomes specified in the ICF (Pollard, Johnston, and Dieppe 2006). In this study we used DCV to identify the ICF outcomes measured by the CPG.

\section{Method}

Design

Participants matched the seven items from the CPG to the definitions of the impairment, activity limitations and participation restrictions constructs from the ICF model. The study was cross-sectional and involved a postal questionnaire.

\section{Participants}

It has been suggested that between 2-20 judges should be used in judgement tasks (Lynn 1986; Waltz, Strickland et al. 1991;Rubio, Berg-Weber et al. 2003).

Consequently, 12 health professionals were recruited from the Institute of Applied Health Sciences at the University of Aberdeen. The 12 potential participants were approached with details of the study and all 12 agreed to participate. Three participants were physicians directly involved in pain research. The remaining nine were academic researchers either specifically involved in the measurement of pain or in pain and disability research in general.

Table 1: Definitions of the three constructs from the ICF Model (WHO, 2001)

\begin{tabular}{|c|l|}
\hline Variable & $\begin{array}{l}\text { Definition } \\
\text { Problems in body function or structures such as } \\
\text { significant deviation or loss }\end{array}$ \\
Impairments (I) & $\begin{array}{l}\text { Body Functions are the physiological functions of the body } \\
\text { systems (including psychological functions) } \\
\text { Body Structures are anatomical parts of the body such as } \\
\text { organs, limbs and their components }\end{array}$ \\
$\begin{array}{c}\text { Activity limitations } \\
(\boldsymbol{A})\end{array}$ & $\begin{array}{l}\text { Difficulties an individual may have in executing } \\
\text { activities } \\
\text { Activity is the execution of a task or action by an individual }\end{array}$ \\
$\begin{array}{c}\text { Participation } \\
\text { restrictions }(\boldsymbol{P})\end{array}$ & $\begin{array}{l}\text { Problems an individual may experience in involvement } \\
\text { in life situations } \\
\text { Participation is the involvement in a life situation }\end{array}$ \\
\hline
\end{tabular}




\section{Materials}

The definitions of the three ICF constructs, namely: impairment, activity limitations, and participation restrictions were taken from the WHO and are given in Table 1. All 7-measurement items from the CPG were assessed and are listed in Table 2.

Table 2: Chronic pain grade questionnaire items

\begin{tabular}{|c|l|}
$\begin{array}{c}\text { Item } \\
\text { Number }\end{array}$ & \multicolumn{1}{c|}{ Item } \\
1 & $\begin{array}{l}\text { How would you rate your pain on a } 0-10 \text { scale at the present time, this } \\
\text { is right now, where } 0 \text { is 'no pain' and } 10 \text { is 'pain as bad as it could } \\
\text { be'? }\end{array}$ \\
2 & $\begin{array}{l}\text { In the past } 6 \text { months, how intense was your worst pain rated on a 0- } \\
10 \text { scale where } 0 \text { is 'no pain' and } 10 \text { is 'pain as bad as it could be'? } \\
\text { In the past } 6 \text { months, on average, how intense was your pain rated on } \\
\text { a 0-10 scale, where } 0 \text { is 'no pain' and } 10 \text { is 'pain as bad as it could } \\
\text { be'? (That is your usual pain at times you were experiencing pain) }\end{array}$ \\
4 & $\begin{array}{l}\text { About how many days in the last } 6 \text { months have you been kept from } \\
\text { your usual activities (work, school, housework) because of this pain? } \\
\text { In the past } 6 \text { months, how much has this pain interfered with your } \\
\text { daily activities rated on a 0-10 scale where } 0 \text { is 'no interference' and } \\
10 \text { is 'unable to carry on activities'? } \\
\text { In the past } 6 \text { months, how much has this pain changed your ability to } \\
\text { take part in recreational, social and family activities where } 0 \text { is 'no } \\
\text { change' and } 10 \text { is 'extreme change'? } \\
\text { In the past } 6 \text { months, how has this pain changed you ability to work } \\
\text { (including housework) where } 0 \text { is 'no change' and 10 is 'extreme } \\
\text { change'? }\end{array}$ \\
6 &
\end{tabular}

\section{Procedure}

Participants received the questionnaire through the post and were instructed to complete the questionnaire in their own time under the constraint that they did not discuss the study with anyone because the study was designed to assess their individual judgements not a collective opinion.

Participants were provided with a brief description of the ICF model and were advised of the need to establish the validity of the measures of each construct within the model. Definitions of the three constructs were presented, side-by-side, at the top of each page of the questionnaire. The CPG items were then listed below the three definitions, in a random but fixed order. Participants were asked to consider carefully the meaning of each item and to decide whether each item matched the definition of each of the three constructs. Participants gave a confidence rating for each judgement on an 11-point scale ranging from $0 \%$ to $100 \%$, rising in $10 \%$ increments. Consequently, each participant provided 3 judgements for each of the 7 
items, i.e. 21 judgements in total. The provision of three judgements for each measurement item is unique to the DCV method. Rather than judge items against a single theoretical construct, the DCV method establishes whether each theoretical construct can be measured discriminately because the method asks judges to indicate the extent to which an item matches each theoretical construct of interest, in this case the three main outcomes identified by the ICF.

\section{Statistical Analysis}

Classification of items: Judgements were coded 1 for a match and -1 for a no match (all questionnaires were completed fully so there was no requirement for missing data to be coded). Each judgement was multiplied by its accompanying confidence rating, expressed as a proportion. Consequently, the weighted judgements ranged from -1 to +1 . One-sample t-tests were used to classify each item to one of the 7 possible combination of constructs, namely: I, A, P, IA, IP, AP or IAP. An item was classified as being related to a construct if its weighted judgement against that construct was significantly greater than zero. Hochberg's correction was used to correct for multiple tests (Hochberg 1988).

Inter-rater reliability: Intraclass correlation coefficients, two-way mixed model with measure of consistency, were used to assess agreement between judges across all seven items and for each construct, i.e. I, A and P judgements. The weighted judgements were used to calculate the ICC.

\section{Results}

Reliability of participant performance

The ICC for all judgements across all seven items was 0.93 (95\% C.I. 0.87-0.97).

The ICC for each construct was as follows, 0.95 (95\% C.I. $0.88-0.99)$ for I judgements, 0.94 (95\% C.I. 0.85-0.99) for A judgements and 0.95 (95\% C.I. 0.860.99) for $P$ judgements. Examination of the contribution of each participant to the ICC, for all judgements and for each construct revealed all participants to be performing equally well; therefore, all 12 participants were included in the subsequent analyses. Similarly, none of the characteristics of the judges, for example, physician or researcher or whether or not the judge was directly involved in research on the measurement of pain affected performance.

\section{Analysis}

The results of the DCV analysis are displayed in Table 3. Before the p-values were corrected for the number of multiple tests performed, only one item was uniquely related to a single construct; item 1 was uniquely classified to the impairment construct. In addition, after correction for multiple tests, items 2 and 3 were also significantly related to the impairment construct only.

Item 5 was uniquely classified as an activity limitations item; its relationship with the participation restriction construct narrowly failed to reach significance after correction for multiple tests. Item 6 was classified as a participation restriction item only; its relationship with both the impairment and activity limitations constructs did not reach the corrected significance levels. 
Table 3: DCV analysis of the Chronic Pain Grade Questionnaire

\begin{tabular}{|c|c|c|c|c|c|c|c|}
\hline \multirow{2}{*}{$\begin{array}{c}\text { CPG Item } \\
\text { Number }\end{array}$} & \multirow{2}{*}{$\begin{array}{l}\text { Classificat } \\
\text { ion }\end{array}$} & \multicolumn{2}{|c|}{ Impairment } & \multicolumn{2}{c|}{ Activity limitations } & \multicolumn{2}{c|}{$\begin{array}{c}\text { Participation } \\
\text { restrictions }\end{array}$} \\
\cline { 2 - 8 } & $\mathbf{t}$ & $\mathbf{p}$ & $\mathbf{t}$ & $\mathbf{p}$ & $\mathbf{t}$ & $\mathbf{p}$ \\
\hline 2 & $\mathrm{I}$ & 4.54 & $\mathbf{0 . 0 0 1}$ & -0.63 & n.s. & -1.31 & n.s. \\
3 & $\mathrm{I}$ & 5.28 & $\mathbf{0 . 0 0 1}$ & -1.03 & n.s. & -2.29 & $0.04^{\mathrm{a}}$ \\
4 & $\mathrm{I}$ & 4.59 & $\mathbf{0 . 0 0 1}$ & -2.50 & $0.03^{\mathrm{a}}$ & -1.62 & n.s. \\
5 & $\mathrm{AP}$ & -2.25 & $0.05^{\mathrm{a}}$ & 18.14 & $\mathbf{0 . 0 0 1}$ & 5.86 & $\mathbf{0 . 0 0 1}$ \\
6 & $\mathrm{~A}$ & -1.65 & n.s. & 26.53 & $\mathbf{0 . 0 0 1}$ & 3.36 & $0.006^{\mathrm{a}}$ \\
7 & $\mathrm{P}$ & -2.24 & $0.05^{\mathrm{a}}$ & 2.71 & $0.02^{\mathrm{a}}$ & 39.68 & $\mathbf{0 . 0 0 1}$ \\
& AP & -1.58 & n.s. & 5.69 & $\mathbf{0 . 0 0 1}$ & 27.44 & $\mathbf{0 . 0 0 1}$ \\
\hline
\end{tabular}

I=Impairment; $A=$ Activity limitations; $P=$ Participation restrictions. $d f=11$ throughout. $n . s .=$ not significant. ${ }^{a}$ not significant, at 0.05 level, after Hochberg's correction for multiple tests

Items 4 and 7 were significantly related to the activity limitations and participation restrictions constructs. The marginal relationship of item 4 with the impairment construct failed to reach significance after correction for multiple tests.

\section{Discussion}

The study demonstrated that the CPG measures all three ICF outcomes. Individual items within the CPG were able to measure a single outcome $(3 \mathrm{xl}, 1 \mathrm{XA}, 1 \mathrm{XP})$ but other items measured multiple outcomes (2XAP). The CPG is, therefore, able to operationalise the ICF because it contains individual items that represent pure measures of I, A and P. The consistency with which the judges matched CPG items to each ICF construct indicates the DCV method was operating in a robust and reliable manner. Further, the lack of a relationship between the personal characteristics of the judges and their pattern of responses further supports the reliability of the data. Performance on a DCV task may be influenced by the actual relationship between the measurement items and the theoretical constructs of interest, and also by the pre-existing knowledge and beliefs of the judges. In this case the personal attributes of the judges most likely to affect their judgement, for example, their professional experience within the area of pain did not impact on their performance on the DCV task. These data provide further evidence of the reliability of the judgements made in the current study.

The data from the DCV task indicates that the usual method of scoring the CPG does conflate outcomes, for example, items 5, 6 and 7 are used to calculate the disability score but these items were judged to measure activity limitations, participation restrictions and both outcomes respectively. Similarly, item 4 is used to calculate the disability days score but this item was judged to measure activity limitations and participation restrictions, thus confounding the two outcomes. Previous DCV studies have also demonstrated conflation of outcomes in numerous health outcome measures, for example, 12 of the 13 outcome instruments analysed contained mixed items (Pollard, Johnston, and Dieppe 2006). Such conflation is not 
limited to pain measures, the previous DCV study also analysed general health outcome measures such as the SF-36 (Ware, Snow et al. 1993). Eleven of the 36 items in the SF-36 were judged to measure more than one component of the ICF. The pattern of conflation was similar to that found in the CPG in that, 10 of the 11 mixed items conflated activity limitations and participation restrictions, the remaining SF-36 item measured all three ICF components (Pollard, Johnston, and Dieppe 2006). In contrast, CPG items 1,2 and 3, used to measure pain intensity, measure the impairment outcome only. This is, again, consistent with previous work that consistently demonstrates pain intensity items measure the impairment outcome in the ICF (Dreinhofer, Stucki et al. 2004;Cieza, Stucki et al. 2004a;Cieza, Stucki, Weigl, Kullmann, Stoll, Kamen, Kostanjsek, and Walsh 2004b;Pollard, Johnston, and Dieppe 2006).

Combining the CPG disability and intensity scores to produce pain grades results in conflation of I, A and P. This may have important consequences when the CPG is used as an outcome measure in both the assessment of pain in the general population and when used to assess the outcome of intervention trials. Epidemiological studies using the CPG have highlighted the high prevalence of chronic pain in the community (Elliott, Smith, Penny, Smith, and Chambers 1999). An understanding of the relationship between the CPG and the three main health outcomes defined by the ICF enables secondary analyses of these type of data to distinguish between the prevalence of impairment, activity limitations and participation restrictions. Such knowledge would better inform any public health agenda that aimed to reduce disability in the community, either in the form of activity limitations and/or participation restrictions. Further, future studies could be designed to include items able to measure independently the three ICF outcomes, thereby identifying the prevalence of each potential intervention target.

With regard to the assessment of intervention studies, an understanding of the relationship between existing measures, such as the CPG, and the ICF enables secondary analyses of existing datasets to enable the identification of successful interventions. For example, an intervention addressing participation restrictions (e.g. accessing transport) may have appeared ineffective due to insensitive measurement of $P$, or a cognitive behavioural therapy intervention to reduce activity limitations may have been successful but failed to demonstrate improvement on the CPG as only one item measures A without contamination with I or P. Even where a global assessment involving $\mathrm{I}, \mathrm{A}$ and $\mathrm{P}$ is required, the relative weighting of the three components in the CPG may not be appropriate. Secondary analyses of such datasets to identify, where possible, impairment as distinct from activity limitations, as distinct from participation restrictions, may reveal success within interventions previously designated as unsuccessful.

Finally, to date the ICF has not been widely used within the pain literature. However, a manual for the clinical implementation of the ICF is in development and the availability of this manual may promote the use of the ICF (Reed, Lux et al. 2005). That said it should be recognised that the ICF is not in itself an assessment tool, in that it does not specify the measures or protocols to be used in the assessment of a particular patient or health condition. Rather, the purpose of the ICF is to provide a conceptual framework for health professionals which is able to guide the comprehensive but standardised assessment of functioning within their professional area of expertise. The standardisation that accompanies the use of the ICF 
facilitates communication between clinical and other professions and comparison of health outcomes between research studies. The advantage of the results of the DCV analysis is that it allows clinicians and researchers to tailor outcome measurement to their specific needs, while still being able to report the standard assessment.

\section{Acknowledgements}

The Medical Research Council-Health Services Research Collaboration supported this work.

\section{Reference List}

Brockow, T., Cieza, A., Kuhlow, H., Sigl, T., Franke, T., Harder, M., and Stucki, G., Identifying the Concepts Contained in Outcome Measures of Clinical Trials on Musculoskeletal Disorders and Chronic Widespread Pain Using the International Classification of Functioning, Disability and Health as a Reference, Journal of Rehabilitation Medicine, 36 (2004) 30-36.

Cieza, A., Brockow, T., Ewart, T., Amman, E., Kolleritis, B., Chatterji, S., Ustun, T.B., and Stucki, G., linking health-status measurements to the international classification of functioning, disability and health, Journal of Rehabilitation Medicine, 34 (2002) 205-210.

Cieza, A., Stucki, G., Weigl, M., Disler, P., Jackel, W., Van Der Linden, S., Kostanjsek, N., and De Bie, R., ICF Core Sets for Low Back Pain, Journal of Rehabilitation Medicine, 36 (2004a) 69-74.

Cieza, A., Stucki, G., Weigl, M., Kullmann, L., Stoll, T., Kamen, L., Kostanjsek, N., and Walsh, N., ICF Core Sets for Chronic Widespread Pain, Journal of Rehabilitation Medicine, 36 (2004b) 63-68.

Dreinhofer, K., Stucki, G., Ewert, T., Huber, E., Ebenbichler, G., Gutenbrunner, C., Kostanjsek, N., and Cieza, A., ICF Core Sets for Osteoarthritis, Journal of Rehabilitation Medicine, 36 (2004) 75-80.

Elliott, A.M., Smith, B.H., Penny, K.I., Smith, W.C., and Chambers, W.A., The Epidemiology of Chronic Pain in the Community, Lancet, 354 (1999) 1248-1252.

Finger, M.E., Cieza, A., Stoll, J., Stucki, G., and Huber, E.O., Identification of Intervention Categories for Physical Therapy, Based on the International Classification of Functioning, Disability and Health: a Delphi Exercise, Physical Therapy, 86 (2006) 1203-1220.

Hochberg, Y., A sharper Bonferroni procedure for multiple tests of significance, Biometrika, 75 (1988) 800-803.

Johnston, M. and Pollard, B., Consequences of disease: testing the WHO international classification of impairments, disabilities and handicaps (ICIDH) model, Social Science \& Medicine, 53 (2001) 1261-1273.

Lynn, M.R., Determination and quantification of content validity., Nursing Research, 
35 (1986) 382-385.

Pollard, B., Johnston, M., and Dieppe, P., What do osteoarthritis heath outcome instruments measure? Impairment, activity limitation or participation restriction?, Journal of Rheumatology, 33 (2006) 757-763.

Reed, G.M., Lux, J.B., Bufka, L.F., Trask, C., Peterson, D.B., Stark, S., Threats, T.T., Jacobson, J.W., and Hawley, J.A., Operationalizing the International Classification of Functioning, Disability and Health in Clinical Settings, Rehabilitation Psychology, 50 (2005) 122-131.

Rubio, D.M., Berg-Weber, M., Tebb, S.S., Lee, E.S., and Rauch, S., Objectifying content validity: Conducting a content validity study in social work research, Social Work Research, 27 (2003) 94-104.

Steiner, W.A., Ryser, L., Huber, E., Uebelhart, D., Aeschlimann, A., and Stucki, G., Use of the ICF Model as a Clinical Problem-Solving Tool in Physical Therapy and Rehabilitation Medicine, Physical Therapy, 82 (2002) 1098-1107.

Stucki, G., Ewert, T., and Cieza, A., Value and Application of the ICF in Rehabilitation Medicine, Disability and Rehabilitation, 25 (2003) 628-634.

Vonkorff, M., Dworkin, S.F., and Leresche, L., Graded Chronic Pain Status - an Epidemiologic Evaluation, Pain, 40 (1990) 279-291.

Vonkorff, M., Ormel, J., Keefe, F.J., and Dworkin, S.F., Grading the Severity of Chronic Pain, Pain, 50 (1992) 133-149.

Waltz, C.W., Strickland, O.L., and Lenz, E.R., Measurement in nursing research., Vol. F.A. Davis Co., Philadelphia, P.A., 1991.

Ware, J.E., Snow, K.K., Kosinski, M., and Gandek, B., SF 36 health survey. Manual and interpretation guide, Vol. The Health Institute, Boston, MA, 1993.

Weigl, M., Cieza, A., Harder, M., Kostanjsek, N., and Stucki, G., Linking Osteoarthritis-Specific Health-Status Measures to the International Classification of Functioning, Disability, and Health (Icf), Osteoarthritis and Cartilage, 11 (2003) 519523.

World Health Organisation, International classification of functioning, disability and health: ICF, World Health Organisation, Geneva, 2001. 